\title{
A agricultura familiar em Portugal: rupturas e continuidades ${ }^{1}$
}

\author{
Renato Miguel do Carmo²
}

\begin{abstract}
Resumo: Em Portugal, as ciências sociais têm estudado a agricultura familiar a partir de um modelo de interpretação dualista que acentua as diferenças inter-regionais, marginalizando, até certo ponto, o significado sociológico de algumas continuidades que se estabeleciam (e se estabelecem) entre as zonas do Norte e do Sul ou entre o Litoral e o Interior. O presente estudo pretende, assim, construir uma perspectiva diferente sobre as modalidades de agricultura familiar em Portugal, procurando identificar, num primeiro momento, uma série de proximidades sociológicas entre os diferentes modos de organização (tradicionais e modernos) das famílias agrícolas e, consequentemente, traçar os eixos para um modelo mais complexo na análise dessas mesmas modalidades.
\end{abstract}

Palavras-chave: Rural, pluriactividade, agricultura familiar, Portugal.

Abstract: The main goal of this paper is to produce a critical analysis regarding the conception of multiple activities in the Portuguese rural society. This work questions the classic vision of the country that delineates a rigid territorial and sociological divisions (for instance, the distinction between Northern and the Southern region) from which it tends to characterize different types of agriculture. Considering this conception, the paper proposes a different perspective that is capable to integrate differences and resemblances, between some of the social and the economic aspects that have redefined the family organization and their workactivities.

Key-words: Rural, multiple activities, family farming, Portugal.

Classificação JEL: R1.

\footnotetext{
${ }^{1}$ Trata-se de um artigo cujo autor é de de Portugal. Dessa forma, o artigo está escrito em português corrente utilizado em Portugal, em que não há correspondência de termos com o português utilizado no Brasil, mesmo para textos científicos em economia.

${ }^{2}$ Sociólogo, investigador auxiliar do Centro de Investigação e Estudos de Sociologia do Instituto Universitário de Lisboa. E-mail: renato.carmo@iscte.pt
} 


\section{Introdução}

A sociedade portuguesa tem sido estudada a partir de um modelo dualista composto por um conjunto de oposições territoriais (Norte - Sul; Litoral Interior) que identificam diferentes realidades sociológicas do país ${ }^{3}$. Este modelo é responsável pela tipificação de diversas áreas rurais e urbanas, com base em análises que evidenciam certas formas de organização social específicas de determinadas zonas que, supostamente, se diferenciam e se opõem a outras estruturas e a outros modos de vida dominantes noutras regiões e localidades.

A oposição entre Norte e Sul caracteriza a sociedade tradicional e estabelece uma diferenciação entre as regiões camponesas e as zonas mediterrânicas de cariz latifundista ${ }^{4}$, respectivamente. A segunda dualidade emerge na análise sociológica a partir da década de 60 e pretende caracterizar a modernização da sociedade que se centraliza principalmente em certas zonas litorais 5 .

A consonância entre a organização social e espacial, identificada por este modelo, contribuiu para que se enfatizasse fundamentalmente as rupturas existentes entre o Norte e o Sul ou entre o Litoral e o Interior, ofuscando, de certo modo, as continuidades sociais e culturais que se estabelecem entre estas áreas territoriais.

Um dos elementos fulcrais a partir do qual se compôs essa diferenciação relaciona-se com a análise das diferentes modalidades de agricultura familiar. Assim, no país tradicional as regiões rurais do Norte sempre se caracterizaram como sociedades fortemente estruturadas pelo modo de organização das famílias agrícolas; enquanto que, em relação ao Sul, sobretudo no Alentejo, se descurou, até certo ponto, a importância das modalidades de agricultura familiar.

Por outro lado, os intensos processos de industrialização e de urbanização que emergiram a partir dos finais dos anos 50 , principalmente nas zonas do Norte e do Centro litoral, afectaram as tradicionais formas de agricultura familiar e provocaram uma série de recomposições sociais na população camponesa.

Ao longo do presente texto, serão questionados os fundamentos destas visões paradigmáticas do mundo rural e da agricultura familiar em Portugal. De modo a aprofundar e a contextualizar a análise, serão recorridos aos estudos que estão sendo desenvolvidos sobre a evolução da composição social no Alentejo. Habitualmente esta região é considerada das mais homogéneas do país (em termos socioeconómicos e culturais) o que, em parte, se deve aos esquemas de tipificação dualistas que tendem a simplificar o significado da realidade social alentejana por oposição a outras áreas regionais.

\footnotetext{
${ }^{3}$ A este respeito ver Carmo (2007).

${ }^{4}$ Nos anos 40, Orlando Ribeiro publica a obra Portugal, o Mediterrâneo e o Atlântico na qual identifica e caracteriza esta oposição territorial.

${ }^{5}$ Esta visão foi difundida primeiramente por A. Sedas Nunes (1964).
} 


\section{A agricultura familiar tradicional: o caso da região alentejana}

Até aos anos 50 do século anterior, tende-se a definir a situação socioeconómica do país agrícola a partir da diferenciação entre agricultura familiar predominante a Norte, por oposição à agricultura de tipo patronal ou latifundiária reinante a Sul ${ }^{6}$. A primeira é representativa da sociedade camponesa, onde a actividade agrícola era fundamentalmente de subsistência e determinada a partir do espaço doméstico e familiar. Este tipo de sociedade compreendia uma estrutura social relativamente homogénea, na qual a desigualdade social se estabelecia entre a classe dos pequenos agricultores e a dos lavradores mais abastados, que possuíam maior porção de terra e utilizavam na produção agrícola mais meios de trabalho. Por seu turno, a percentagem de jornaleiros ${ }^{7}$ era claramente menor relativamente às zonas do Sul ${ }^{8}$.

Em contrapartida, na sociedade agrária do Sul a estrutura social era bem mais polarizada entre duas classes principais: os grandes proprietários e os trabalhadores assalariados que representavam parte substancial da população agrícola ${ }^{9}$. Na análise da sociedade agrária alentejana ${ }^{10}$, o critério utilizado para diferenciar as várias camadas sociais define-se através da distinção entre os grupos que possuem propriedade (jurídica e/ou económica) e aqueles que não são proprietários, detendo como único recurso a força de trabalho.

A dualização da realidade rural e agrícola da sociedade portuguesa, a partir dos critérios mencionados, contribuiu para uma simplificação analítica que acabou por encobrir uma série de situações impuras nas quais se pode identificar a coexistência, em algumas famílias e grupos sociais, de situações bem diferentes e até contraditórias.

A realidade social alentejana é habitualmente analisada e apresentada como sendo bastante hegemónica. Os diversos estudos sobre a composição social desta região salientam fundamentalmente o significado da polarização social,

\footnotetext{
${ }^{6}$ Alguns estudos relativamente recentes sobre a realidade social e económica de Portugal, dos anos 30 aos anos 50, ainda vincam esta perspectiva dualista, cf. Baptista (1993), Rosas (1994).

7 Trabalhadores agrícolas que recebiam à jorna (ao dia).

${ }^{8}$ Para a análise das desigualdades sociais no meio rural nortenho ver as obras de O'Neill (1984) e de Karin Wall (1998) que estudaram a evolução do sistema de estratificação social em duas aldeias transmontanas e em duas aldeias minhotas (respectivamente). Ambos salientam a importância, por vezes descurada, que a classe dos jornaleiros teve na estrutura social destas aldeias até meados dos anos 60 .

${ }^{9}$ Entre estes dois estratos alguns autores identificaram uma classe intermédia que segundo Cutileiro (1977) é composta essencialmente pelos seareiros, mais adiante será caracterizado este grupo social.

${ }^{10}$ Região latifundiária localizada a Sul de Portugal.
} 
identificando o doloroso modo de vida das famílias de trabalhadores, face à riqueza e ostentação das famílias latifundiárias.

No entanto, por intermédio do estudo apurado de dados estatísticos da época, assim como da análise de algumas monografias realizadas nos anos 30 e 40 , pode-se considerar que, até aos meados dos anos 60 , a vida social de parte das famílias agrícolas desta região era constituída por um conjunto diversificado de actividades de exploração e de organização do trabalho. Esta diversidade derivava da natureza do estatuto da propriedade e das formas de produção e de trabalho agrícola.

Normalmente refere-se a ausência de mecanização e o carácter absentista do latifundiário alentejano para justificar o recurso a grandes contingentes de mão de obra assalariada, até praticamente a meados dos anos 60 do séc. XX. Todavia, é importante referir que existia um outro recurso importante, por parte dos grandes proprietários, que passava pela celebração de diferentes contratos de arrendamento e de modalidades de parceria.

Parte das terras eram arrendadas a grandes e médios lavradores rendeiros, que em muitos casos exploravam a totalidade da propriedade, mas também podiam ser cedidas, em parcelas mais pequenas, aos seareiros ${ }^{11}$. Este grupo social teve uma importância decisiva no processo de arroteamento e de desflorestação da charneca alentejana ${ }^{12}$ e na generalização da plantação da cultura do trigo (desde a segunda metade do séc. XIX).

Como referem alguns autores, geralmente os proprietários, e também os grandes lavradores rendeiros, cediam as terras menos produtivas das suas explorações aos seareiros fazendo com que, proporcionalmente, estes acabassem por obter lucros mais baixos com o cultivo de cereais ${ }^{13}$. Para minimizar os custos, $\mathrm{o}$ seareiro normalmente possuía alguns meios de produção (animais de trabalho, parelha de muares), e recorria principalmente ao trabalho familiar, o que lhe permitia assegurar por conta própria a exploração da terra arrendada. De facto, poucos eram aqueles que empregavam regularmente mão de obra assalariada ${ }^{14}$.

\footnotetext{
${ }^{11}$ Originariamente o seareiro pode ser definido como o agricultor que cultivava cereais em terra alheia sob pagamento de $1 / 4$ ou $1 / 3$ da produção cerealífera ao proprietário, segundo um contrato que poderia ir de um aos três anos. A propósito do seareiro ver Baptista (1980), Galvão (1949) e Pinto (1941).

${ }^{12}$ Zona de mato que se encontra na região mediterrânica, composta por arbustos muito densos e de díficil penetração.

${ }^{13}$ Como demonstram J. Mira Galvão (1949) e J. Machado Pais et al (1976), da maior parte das parcerias praticadas resultava uma situação de prejuízo para o seareiro.

${ }^{14}$ Segundo os dados do Inquérito às Explorações Agrícolas de 1952-4 no Alentejo, mais de $90 \%$ dos seareiros não empregavam regularmente mão de obra assalariada.
} 
Normalmente o seareiro e a sua família encontravam-se numa situação social impura em que confluíam diferentes tipos de actividade agrícola ${ }^{15}$, em muitos casos o agricultor conjugava a actividade de seareiro com a de pequeno proprietário agrícola e/ou com a de assalariado agrícola ${ }^{16}$.

A situação de pluriactividade agrícola obrigava a uma estratégia familiar de divisão do trabalho, na qual os vários elementos do agregado se repartiam perante um conjunto diversificado de funções, podendo mudar várias vezes ao longo do ano a tarefa exercida por cada um.

Neste sentido, pode-se dizer que a categoria de seareiro não representava uma situação social homogénea, pelo contrário, estes indivíduos ocupavam na maior parte dos casos aquilo que Wright (1994) define como "um lugar contraditório de classe", na medida em que podiam alternar entre a situação de trabalhador por conta própria (e por vezes de empregador) e a situação de trabalhador por conta de outrem ${ }^{17}$.

A pluriactividade agrícola era um factor importante para a manutenção e resistência da agricultura familiar no Alentejo. Esta estruturava-se em torno de três eixos: o arrendamento agrícola, o trabalho assalariado e a pequena exploração agrícola. De facto, a pequena propriedade (que era e é maior em número face à grande propriedade que ocupa maior área) teve e ainda tem uma certa importância na região. Contudo, a maior parte destas explorações eram claramente insuficientes para sustentar a família do agricultor.

O trabalho por conta própria nestas pequenas propriedades não representava a actividade principal do agricultor que se via na contingência de recorrer ao trabalho assalariado e/ou ao arrendamento de outras explorações agrícolas. Deste modo, pode-se concluir que a pequena exploração era um factor que contribuía para o desenvolvimento de estratégias familiares de pluriactividade e de plurirendimento de carácter agrícola (CARMO, 2007).

Neste sentido, embora a natureza da agricultura familiar no Alentejo fosse bastante diferente da que predominava nas regiões de minifúndio, ela continha um conjunto de características que a aproximavam do modo de vida camponês das

\footnotetext{
${ }^{15}$ Como demonstram algumas monografias da época - de Henrique de Barros, sobre a vila de Cuba (1934) e, sobretudo, de Bugalho Pinto, que estudou o seareiro na aldeia de Cabeça Gorda (1941) - em determinados sectores da pequena e média agricultura era habitual encontrar-se situações de pluriactividade e de plurirendimento.

${ }^{16}$ Por vezes os seareiros também realizavam trabalhos por fora ("vendendo jeiras"), isto é, utilizavam os seus próprios meios de trabalho (a parelha de muares ou de burros ou, com menor expressão, a junta de bois) para lavrar noutras explorações ou para serviços de transporte.

${ }^{17}$ Para demonstrar a importância e a capacidade de resistência que a situação de seareiro teve na estrutura social agrícola, convém referir que, em 1952, foram ainda recenseados cerca de 18.286. Nesta altura, em muitas zonas do Alentejo o grupo social dos seareiros tinha ainda um peso superior a outras classes sociais agrícolas (nomeadamente à dos patrões agrícolas e/ou à dos camponeses isolados).
} 
sociedades rurais do Norte. Características essas que, independentemente das causas, tinham a ver fundamentalmente com o carácter tradicional e pouco propenso para o desenvolvimento da actividade agrícola, tanto a Norte como a Sul do país.

Por este motivo, apesar de fazer sentido demarcar o Norte e o Sul, em função do tipo de agricultura e das classes sociais dominantes em cada zona, entende-se que essa divisão analítica não deve ter um carácter absoluto que provoque uma simplificação na leitura da realidade social e económica vivida nos campos até meados dos anos 60.

\section{As formas modernas de pluriactividade}

Numa outra linha de análise surgiram um conjunto de estudos monográficos que tentaram identificar o modo como algumas regiões rurais, localizadas próximo do litoral, foram passando por um processo de urbanização e de alteração das estruturas sociais. Começando pelo Norte do país, salientam-se o estudo de Karin Wall (1998), que analisa a vida das famílias de duas aldeias ${ }^{18}$ localizadas no Baixo Minho; os trabalhos de Ferreira de Almeida (1999 [1986]) e de Madureira Pinto (1985) sobre uma aldeia situada nos limítrofes da área metropolitana do Porto; no Centro, destaca-se a análise de Pedro Hespanha (1994) sobre as localidades rurais da zona de Coimbra; os estudos de Nelson Lourenço (1991), Moisés Espírito Santo (1999) e António Gama (1987), que se debruçaram em localidades da região de Leiria; e, finalmente, a Sul, a monografia de Robin Jekins (1979), que estudou os processo de mudança de uma aldeia algarvia.

Todos estes trabalhos caracterizam as mudanças que se desenrolam em zonas rurais localizadas não muito longe de determinadas zonas urbanas e/ou industriais de média ou de grande dimensão que, por seu lado, estão a sofrer um intenso processo de modernização socioeconómica. As mudanças vividas nestas freguesias rurais dizem respeito não só à alteração dos modos de produção agrícola, que se mecanizam e tendem a integrar uma lógica de produção capitalista, mas também às modalidades de industrialização e de terciarização que se generalizam e tendem a afectar as economias locais.

Estas áreas (nomeadamente das zonas do Porto, Coimbra e Leiria) podem ser designadas como zonas peri-urbanas, na medida em que são alvo de uma série de mecanismos de modernização relacionados com o desenvolvimento tecnológico e com a difusão de novas possibilidades de comunicação e de transporte, contribuindo, assim, para a utilização de novas formas de energia empregues nas diferentes modalidades de produção (GAMA, 1987).

Recorrendo à formulação de A. Sedas Nunes (1964), pode-se dizer que a noção de zona peri-urbana designa todo um conjunto de processos que se generalizam na sociedade moderna e tenderam a expandir-se e a condicionar a

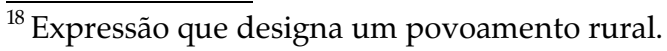


realidade socioeconómica das regiões mais tradicionais (localizadas no interior do país). A proximidade espacial, que se intensifica devido às novas formas de mobilidade e de transporte, torna-se assim o factor responsável pela difusão da modernidade nestas zonas periféricas. A nível sociológico, estas mudanças foram identificadas sobretudo na alteração do sistema de estratificação social das sociedades rurais e dos modos e estilos de vida tradicionais.

O fenómeno de mudança mais estudado nestas zonas relaciona-se com a pluriactividade familiar (ALMEIDA, 1999; BARROS, 1986; BARROS \& MENDES, 1983; CAVACO, 1981; GAMA, 1987; HESPANHA, 1994; LIMA, 1990; LOURENÇO, 1991; SOBRAL 1999), que leva ao surgimento de uma nova classe social denominada de campesinato parcial. Esta posição de classe tornou-se maioritária em muitas das localidades estudadas. Assim, parte das famílias camponesas tendem a manter a sua exploração agrícola, ao mesmo tempo que alguns elementos do agregado (sobretudo homens) trabalham em sectores e empresas não agrícolas, situadas em muitos casos fora da povoação (nos centros urbanos mais próximos ou em outras zonas rurais que sofrem processos de industrialização difusa). Esta situação é responsável pela intensificação das deslocações pendulares entre as aldeias e os espaços urbanos e/ou industrializados.

Por outro lado, para além da reestruturação do campesinato local, aumenta o peso das classes ligadas quer ao sector terciário, como é o caso da nova pequena burguesia, quer ao sector secundário (patronato e operariado industrial). O reforço destas classes é representativo de uma efectiva modernização socioeconómica que contribui para a difusão dos modos e estilos de vida urbanizados. De facto, os residentes das freguesias rurais que trabalham nos centros urbanos acabam por importar estilos de vida e valores característicos das cidades.

Todos estes processos concretizam, por um lado, o modo como a modernização alastra e se difunde pelas zonas periféricas e rurais, alterando as estruturas sociais e os estilos de vida das populações locais; mas, por outro lado, reflectem uma série de factores de resistência às formas de produção agrícola capitalistas e empresariais, que resultam na manutenção da agricultura familiar como um elemento crucial na sustentabilidade das populações rurais.

\section{Um conceito bivalente}

A maior parte dos estudos, referidos no ponto anterior, debruçou-se fundamentalmente no conceito de pluriactividade familiar, com o intuito de caracterizar um conjunto de mudanças socioeconómicas e culturais que se desenvolvem em determinadas zonas rurais. Estes contributos monográficos comprovam assim a tese dualista, evidenciada por A. Sedas Nunes (1964), a partir da qual se perspectiva uma contínua penetração de factores de modernização na sociedade tradicional (que representava a maior parte das zonas do interior do país). 
Esses processos alteram o modo de organização da família, que tem de conciliar a manutenção da actividade agrícola e a divisão do trabalho, cada vez mais complexa, entre os vários elementos do agregado. Por outro lado, os movimentos pendulares (diários ou sazonais) para fora da localidade obrigam aos que ficam (as mulheres na maior parte dos casos) a um esforço redobrado na gestão das actividades agrícolas, domésticas e educacionais.

Desta feita, é atribuído à pluriactividade familiar um sentido de ruptura face ao modo de vida camponês e às formas tradicionais de organização no seio da família. Contudo, o significado sociológico dessa ruptura deverá ser relativizado, na medida em que ela representa uma alteração principalmente ao nível do conteúdo das modalidades de pluriactividade, e não tanto ao da sua organização formal.

Como referido anteriormente, na sociedade tradicional, a prática da pluriactividade familiar e o recurso ao plurirrendimento eram bastante intensos em faixas importantes da população rural residente não só no Alentejo, como também nas regiões do Norte. Na verdade, como descreve Brian O'Neill (1984), até ao advento da emigração (que se generaliza a partir dos anos 50 do século XX) a proporção de jornaleiros nas aldeias transmontanas ${ }^{19}$ era bastante considerável, tal como ilustram os dados dos recenseamentos relativamente às regiões localizadas a Norte $^{20}$. Segundo O. Baptista esses dados indicam que "em largas manchas da zona de agricultura familiar [a Norte] a maior parte dos assalariados agrícolas eram elementos (filhos) de famílias agricultoras cujas explorações não permitiam o sustento de todo o agregado familiar" (BAPTISTA, 1993, p. 334).

A pluriactividade era, assim, um factor essencial na vida dos campos e que, muitas vezes, se encontrava associada a fenómenos de migração sazonal de camponeses que se dirigiam em massa para as regiões latifundiárias do Sul, como era o caso dos "(...) movimentos para as regiões de grande cultura de trigo e de arroz, geralmente com carência de braços nos momentos culminantes das fainas agrícolas" (RIBEIRO, 1999, p. 754).

Deste modo, pode estabelecer-se uma certa continuidade entre a forma de organização da família camponesa tradicional, que à medida das possibilidades conseguia diversificar as actividades agrícolas entre os elementos do seu agregado, e as famílias de campesinato parcial que, devido à modernização, podem auferir de diferentes fontes de rendimento resultantes da actividade em diversos sectores não agrícolas. De facto, as mudanças verificam-se sobretudo na natureza e no conteúdo das actividades exercidas, que passam a compreender componentes de modernidade, o que provoca fortes alterações socioeconómicas e culturais nos modos e estilos de vida (ALMEIDA, 1999; CARMO, 2009).

\footnotetext{
${ }^{19}$ Situadas na zona nordeste de Portugal.

${ }^{20}$ Segundo os dados dos Recenseamentos Gerais à População, nesta área do país os assalariados contabilizavam em 1950 e 1960 cerca de 47\% e 46\% (respectivamente) da população agrícola (BAPTISTA, 1993, p. 405).
} 
Neste sentido, o conceito de pluriactividade incorpora uma dimensão bivalente: por um lado, identifica um conjunto de rupturas entre a sociedade tradicional e os processos de modernização, mas por outro lado, desvela uma série de continuidades entre o modo de vida dos camponeses do Norte (e os seareiros do Alentejo) ou entre as famílias agrícolas tradicionais e as modernas.

O significado bivalente do conceito de pluriactividade permite, assim, construir uma visão diferente da agricultura familiar e do meio rural português (tradicional e contemporâneo).

Noutro lugar teve-se a oportunidade de demonstrar que a forma socioespacial do processo de modernização e de urbanização da sociedade portuguesa tende assemelhar-se a uma configuração em arquipélago, na qual emergem localidades detentoras de um relevante dinamismo socioeconómico e cultural, como é o caso de algumas cidades do interior ou das zonas de industrialização difusa (Carmo, 2006).

Esta alteração gradual, que começa a esboçar-se a partir da década de 80 (do século XX), não só condiciona a organização espacial e os modos de vida urbanos nas cidades médias, como vai provocar complexas mutações nos espaços rurais e na relação que estes estabelecem com as zonas mais urbanizadas.

As mudanças ocorridas na sociedade exigem uma análise pluridimensional que não exclua os elementos dualistas, mas tenha a preocupação de integrar uma perspectiva mais complexa dos fenómenos em causa.

Em relação à temática que está sendo tratada, pode-se dizer se tem assistido a uma pulverização das modalidades de pluriactividade moderna pelas mais variadas localidades do país ${ }^{21}$. De facto, se levado em conta os dados do Recenseamento Agrícola de 1999, verifica-se que não existe grande disparidade inter-regional entre as percentagens de elementos familiares que exercem uma actividade exterior à exploração agrícola ${ }^{22}$. Estes dados comprovam, de certo modo, a generalização da pluriactividade familiar que deixou de ser específica das zonas rurais localizadas próximo da faixa litoral.

Assim, apesar das diferenças ainda salientes ao nível da estrutura fundiária, entre as zonas de minifúndio (predominantes a Norte) e as zonas de latifúndio situadas a Sul, identificam-se um conjunto de aproximações sociológicas entre estas áreas. A progressiva mecanização e modernização da agricultura e o decréscimo constante de população agrícola fizeram com que o número de trabalhadores agrícolas tivesse descido substancialmente, influenciando para o reforço do peso de agricultores isolados e autónomos que não empregam mão de obra exterior e recorrem fundamentalmente ao trabalho familiar.

\footnotetext{
${ }^{21}$ A este respeito refira-se o importante estudo de M. Carlos Silva (1998) que analisa as consequências da modernização da agricultura e as alterações das modalidades de pluriactividade e plurirendimento nas famílias residentes em duas aldeias minhotas.

${ }^{22}$ A proporção ronda os $30 \%$ em praticamente todas as regiões com a excepção de Trás-os-Montes cuja percentagem é um pouco inferior (24).
} 
Esta tendência afectou principalmente o Alentejo que, embora mantenha o maior peso (a nível nacional) na proporção de empresários agrícolas, vê aumentar substancialmente a percentagem de agricultores autónomos ${ }^{23} \mathrm{e}$ diminuir claramente a proporção de assalariados agrícolas ${ }^{24}$. Neste sentido, a representação da agricultura familiar aumenta consideravelmente nesta região, comparativamente ao que acontecia há três décadas, quando o número de trabalhadores agrícolas era largamente maioritário.

\section{Pluriactividade no Alentejo: entre as décadas de 70 e de 90}

Ao analisar, mais uma vez, a região alentejana, detecta-se que a natureza das formas de pluriactividade se tem tornado mais diversificadas e complexas. $\mathrm{O}$ Alentejo sofreu nestas últimas três décadas uma série de mudanças profundas nas estruturas sociais. A mais marcante diz respeito à estrondosa redução de activos ocorrida no sector agrícola, que passou a ser claramente minoritário. De facto, desde os finais dos anos 50, a população agrícola familiar alentejana tem vindo a decrescer de forma muito acentuada. No entanto, nas décadas de 80 e 90 que foram verificadas as perdas mais substanciais. Segundo os dados dos recenseamentos da agricultura, entre 1979 e 1999, a população agrícola familiar do Alentejo diminuiu 31\% (decresceu 6\% nos anos 80 e 27\% na década seguinte).

Se levado em conta somente o número de produtores agrícolas, observa-se uma diminuição similar que, no entanto, afecta diferentemente as mulheres e os homens. Durante este período, identifica-se um crescimento generalizado do número de produtoras agrícolas, que crescem 36\% nos anos 80 e 13\%, na década seguinte. Apesar desta evolução, o volume de produtoras ainda é relativamente residual, crescendo de 3.703 (em 1979) para 5.691 (em 1999), isto é, se naquele ano estas representavam cerca de $8 \%$ do total de produtores agrícolas, neste último correspondem a $12 \%$.

Contudo, apesar do decréscimo generalizado de população, verifica-se que proporcionalmente, se denota uma menor redução em relação ao conjunto de efectivos que constituem as famílias agrícolas relativamente à diminuição ocorrida no número de activos empregados neste sector (nomeadamente, trabalhadores assalariados). Isto é, as famílias demonstram alguma capacidade

\footnotetext{
23 "Pessoa singular que, permanente ou predominantemente, utiliza a actividade própria ou de pessoas do seu agregado doméstico, sem recurso ou com recurso excepcional ao trabalho assalariado", cf. Instituto Nacional de Estatística, Recenseamento Geral da Agricultura de 1999.

${ }^{24}$ Segundo os dados do Recenseamento Geral Agrícola de 1999, no Alentejo, produtores autónomos rondam os $67 \%$, os empresários agrícolas representam cerca de $6 \%$ e os trabalhadores agrícolas, $28 \%$.
} 
de "resistência" que se espelha na manutenção percentual de elementos que trabalham com alguma regularidade na exploração agrícola.

Assim, se em 1979 cerca de somente $26 \%$ da população agrícola familiar não exercia qualquer actividade na exploração, observa-se que em 1999 essa proporção sobe ligeiramente para $29 \%$. Tendo em conta que neste sector a população activa diminuiu fortemente, é possível dizer que o trabalho familiar ganha uma importância relevante que não pode ser descurada. De qualquer modo, a qualidade desse trabalho é menos permanente face à realidade de 1979, em que cerca de $16 \%$ da população familiar agrícola desenvolvia uma actividade na exploração a tempo completo (em 1999 apenas 9\% se dedicam a tempo inteiro). Este dado relaciona-se, em parte, com a mecanização do sector, que se intensifica a partir da década de 60 do século XX, e afecta também os produtores individuais.

Para além da evolução negativa que marca profundamente a população agrícola assiste-se, nestas duas décadas, a uma alteração clara na estrutura e no modo de organização social da vida agrária. Um dos aspectos mais determinantes diz respeito às modalidades de pluriactividade, que se modificaram radicalmente.

$\mathrm{Na}$ verdade, como foi referido, o sistema agrário de cariz latifundiário organizava-se e reproduzia-se em torno de dois pilares fundamentais: o recurso relativamente generalizado, por parte dos grandes agricultores, aos contratos de arrendamento e de parceria de terra, e ao emprego maciço de trabalhadores assalariados. Era um sistema de natureza pré-capitalista que aliava os modos de exploração tradicionais (investindo muito pouco em factores de produção modernizantes) a uma lógica de mercantilização a grande escala (regional e nacional).

Este sistema, apesar de se autoreproduzir tendo por base práticas sociais fortemente coercivas e autoritárias, que não possibilitavam o desenvolvimento de sectores alternativos à agricultura, permitia a proliferação de modalidades diversificadas de pluriactividade agrícola.

Nestas últimas duas décadas, no entanto, assiste-se a uma quebra na proporção de população familiar que conjuga o trabalho na exploração agrícola com o exercício de uma actividade exterior. Em 1979, cerca de 35\% dos elementos encontravam-se em situação de pluriactividade. Esta percentagem decresce em 1981 para $29 \%$, mantendo-se a este patamar em 1999. A variação negativa que se verifica na população em situação de pluriactividade, ocorrida durante a década de 80 , é muito superior à que se observa na população agrícola total.

Este dado tem a ver principalmente com a redução da pluriactividade de cariz agrícola. De facto, em 1979, cerca de $41 \%$ da população em situação de pluriactividade exercia outra actividade no sector agrícola (na maior parte dos casos exploravam propriedades em forma de arrendamento e/ou de parceria). Esta proporção diminui para 32\% em 1981 e $21 \%$ em 1999. Em termos numéricos, a taxa de variação é muito negativa: decresce $37 \%$ (entre 1979 e 1989) e $51 \%$ (entre 1989 e 1999). 
Por outro lado, assiste-se a uma efectiva terciarização nas modalidades de pluriactividade. Embora neste caso também se identifique uma diminuição da população que conjuga a exploração agrícola com uma actividade no sector terciário, observa-se, contudo, uma taxa de variação muito menos negativa: de $-2 \%$ e de $-16 \%$, nas respectivas décadas. Deste modo, se em 1979 somente $41 \%$ da população agrícola em situação de pluriactividade exercia uma actividade exterior na área do comércio e dos serviços, já em 1989 e em 1999 esta porcentagem passa para 50 e 57 , respectivamente.

A situação que conjuga a agricultura com o sector secundário mantém o seu nível proporcional, apesar de ter conhecido uma variação negativa superior à ocorrida na modalidade descrita acima: de $-22 \%$ e de $-11 \%$ em cada uma das décadas.

As tendências que foram brevemente descritas neste ponto reflectem a modificação gradual que vem substituindo as formas tradicionais de pluriactividade agrícola por modalidades mais diversificadas, que conjugam o trabalho exercido na exploração agrícola com a generalização de actividades exteriores ao sector. Neste sentido, a agricultura de tipo parcial assente no recurso ao trabalho familiar é numa das características mais salientes do sistema agrário alentejano, à semelhança do que sucede com outras zonas do país, nomeadamente as de minifúndio.

\section{Conclusão}

A definição de oposições bem determinadas entre diferentes áreas territoriais da sociedade portuguesa, resultantes da estruturação de um modelo de interpretação dualista que encontrou correspondência com uma série de estudos monográficos, contribuiu para que a leitura do mundo rural português evidenciasse principalmente as rupturas e descontinuidades inter-regionais. Esta visão enfatizou de tal modo a orgânica interna de certas regiões e comunidades que, por vezes, se fica com a ideia que o país se desmembra em diferentes sociedades quase autónomas entre si.

Assim, no que diz respeito à sociedade tradicional, os estudos construíram um significado restrito da agricultura familiar, enquadrando-a fundamentalmente nas comunidades camponesas das regiões de minifúndio, ao mesmo tempo que se reduziu a sua importância na estruturação das relações sociais e de produção nas zonas de latifúndio localizadas a Sul.

Por seu turno, os trabalhos que se debruçaram sobre as modalidades de modernização do meio rural contribuíram para limitar a amplitude espacial e temporal do conceito de pluriactividade, descurando o seu valor na organização da vida nos campos em zonas do interior do país (tanto a Norte como a Sul).

Neste sentido, torna-se fundamental reequacionar o significado sociológico dos conceitos de agricultura familiar e de pluriactividade, com o intuito de desenvolver uma visão pluridimensional da vida rural e agrícola capaz de estabelecer diversas "pontes" analíticas entre os diferentes contextos e territórios estudados. 


\section{Referências bibliográficas}

ALMEIDA, João Ferreira de. Classes sociais nos campos. Oeiras: Celta Editora, 1999.

BAPTISTA, Fernando Oliveira. A Política Agrária do Estado Novo. Porto: Edições Afrontamento,1993.

BAPTISTA, Oliveira Fernando. Economia do latifúndio - o caso português. In: BARROS, Afonso de (Coord.). A Agricultura Latifundiária na Península. Oeiras: Instituto Gulbenkian de Ciência, 1980.p. 341-372.

BARROS, Afonso de. Do latifundismo à reforma agrária: o caso de uma freguesia do Baixo Alentejo. Oeiras: Instituto Gulbenkian de Ciência, 1986

BARROS, Afonso de, e MENDES, Fernando Ribeiro. Formas de produção e estatutos do trabalho na agricultura portuguesa. Análise Social, v. XIX, nํ75, p. 57-78. 1983.

BARROS, Henrique de. A população e o trabalho agrícolas na freguesia de Cuba. Lisboa: Direcção Geral dos Serviços Agrícolas do Ministério da Agricultura, 1934

CARMO, Renato Miguel do. A construção sociológica do espaço rural: da oposição à apropriação. Sociologias. no 21, p. 252-280. 2009.

CARMO, Renato Miguel do. De aldeia a subúrbio: trinta anos de uma comunidade alentejana. Lisboa: Imprensa de Ciências Sociais, 2007.

CARMO, Renato Miguel do. Cidades Médias: do crescimento demográfico à consolidação territorial. Cidades, Comunidades e Territórios. no 12/13. p. 69 - 82. 2006.

CAVACO, Carminda. A pluriactividade na pequena agricultura portuguesa. Revista Crítica de Ciências Sociais, no7/8, p. 171-193. 1981.

CUTILEIRO, José. Ricos e pobres no Alentejo. Lisboa: Sá da Costa, 1977.

GALVÃO, J. Mira. O seareiro. Beja: Minerva Comercial, 1949.

GAMA, António. Indústria e peri-urbanização. Revista Crítica de Ciências Sociais, no 22 , p. 33-54. 1987.

HESPANHA, Pedro. Com os pés na terra. Porto: Edições Afrontamento, 1994.

JENKINS, Robin. Morte de uma aldeia portuguesa. Lisboa: Querco, 1979.

LIMA, Aida Valadas. Pluriactividade e integração espacial. Sociologia Problemas e Práticas, no 8, p. 55-62. 1990.

LOURENÇO, Nelson. Família rural e indústria. Lisboa: Fragmentos, 1991. 
NUNES, Sedas. Portugal, sociedade dualista em evolução. Análise Social, nº7-8, p. 407-462. 1964.

O'NEILL, Brian Juan. Proprietários, lavradores e jornaleiros: desigualdade social numa aldeia transmontana (1870 - 1976). Lisboa: Dom Quixote, 1984.

PAIS, Machado, et al. Elementos para a história do fascismo nos campos: a campanha do trigo: 1928-38 (I). Análise Social, v. XII, no46, p. 401-473. 1976.

PINTO, Joaquim Bugalho, O seareiro na Freguesia de Cabeça Gorda-concelho de Beja. Dissertação. Instituto Superior de Agronomia da Universidade Técnica de Lisboa. 1941.

PINTO, José Madureira. Estruturas sociais e práticas simbólico-ideológicas nos campos: elementos de teoria e de pesquisa empírica. Porto: Edições Afrontamento, 1985.

ROSAS, Fernando et al.. Estado Novo. In: Mattoso, José (Dir.). História de Portugal vol. VII. Lisboa: Círculo de Leitores, 1994.

RIBEIRO, Orlando; LAUTENSACH, Hermann e DAVEAU, Suzanne, Geografia de Portugal vol. III. 3a ${ }^{a}$ ed.. Lisboa: Edições João Sá da Costa, 1999.

SANTO, Moisés Espírito. Comunidade ao Norte do Tejo: seguido de vinte anos depois. Lisboa: Universidade Nova de Lisboa, 1999.

SILVA, Manuel Carlos. Resistir e adaptar-se: constrangimento e estratégias camponesas no Noroeste de Portugal. Porto: Edições Afrontamento, 1998.

SOBRAL, José Manuel. Trajectos: o presente e o passado na vida de uma freguesia da Beira. Lisboa: Imprensa de Ciências Sociais, 1999.

WALL, Karin. Famílias no campo: passado e presente em duas Famílias do Baixo-Minho. Lisboa: Publicações Dom Quixote, 1998.

WRIGHT, Erik Olin. Análise de classes, história e emancipação. Revista Crítica de Ciências Sociais, no40, p. 3-36. 1994.

\section{Fontes}

Inquérito às Explorações Agrícolas de 1952-4, Instituto Nacional de Estatística. Inquérito às Explorações Agrícolas de 1968, Instituto Nacional de Estatística. Recenseamento Geral da Agricultura de 1979, Instituto Nacional de Estatística. Recenseamento Geral da Agricultura de 1989, Instituto Nacional de Estatística. Recenseamento Geral da Agricultura de 1999, Instituto Nacional de Estatística. 